\title{
University-Industry Linkages as Determinant Of Students' Entrepreneurial Orientation in Rivers State Public Universities
}

\author{
Dr. Ikpesu, Oghenerukevwe Christian \\ Department of Business Education \\ Faculty of Technical and Science Education \\ Rivers State University of Science and Technology
}

\begin{abstract}
Linkages are assuming unusual popularity as a platform for technology transfer, knowledge sharing and seeking support by universities from industry. Thus, the study examined university-industry linkages to determine its resultant implications to students' entrepreneurial orientation in public universities in Rivers States. The population, therefore, consists of 160 academic administrators involve in designing policy frameworks and curriculum reforms that strengthens linkages with industry in their respective universities. Two independent measurement scales having four Likert points contained 13-item each measured the critical contributions of universityindustry linkages and its implications to students' entrepreneurial orientation (EO). The two sets of questionnaire computed with Cronbach Alpha provided 0.87, 0.78 reliability index. Data finally gathered from 150 respondents were analyzed using mean statistics and hypothesis tested with Pearson product moment correlation coefficient and Z-test at 0.05 level of significant showed +0.376 , Zrcal 0.561 and Zrcrit value of 0.195 . In conclusion, the results however affirmed subsisting relationship which significantly underscores the contributions and consequences of universityindustry for developing students' entrepreneurial orientation in public universities. Therefore Governments should strengthen the various linkages policy frameworks to encourage and drive the objectives of entrepreneurship education of producing students with high entrepreneurial contents that can fit well into self-employment and global labour market.
\end{abstract}

Keywords: Linkages, entrepreneurial education, entrepreneurial orientation, entrepreneurship, economic development

\section{INTRODUCTION}

Conventional education system in Nigerian universities largely promotes take-the-job mentality rather than entrepreneurialism and innovation. This is more so as result of lack of strong synergy between university and industry necessary for technology transfer, knowledge sharing and practical enterprise orientation for students. Support from industry to universities has remained minimal over the years compare to funding through the state subventions. As observed, industry accounts for small share of university funding, not more than an average of 5 percent (OECD, 1998) in Gundmund and Michaela (2000). On the other end, universities in Nigeria are confronted with severe cutbacks which limit their power to fund core infrastructure and operational costs. As acknowledged by the International Institute for Educational Planning (IIEP,2000) in developing countries, overall budgets have grown but, according to many cases, resources have shifted from higher to basic education. The difference amongst economies has been closely related to the amount of resources invested in education by countries. Many experts are of the view that universities especially from developing countries undergoing decline in state budget should shift their attention to developing relations with industry and business institution. Thus, universities are expected to rally 
around other critical stakeholders for technical expertise, management, technology, and financial aids. Increasing relevance and competitiveness of universities across the globe is largely determined by their tripartite relationship with Government- industry. Therefore, partnership with strong industrial content in universities is crucial for providing students necessary orientation that will change their long standing take-the-job mentality and channel their mindsets to favour emergence of small and medium business enterprises. However, despite Federal Government several policies, universities continue to witness dwindling linkages with industry. UNIDO (2007) had observed that government policies and their effectiveness play a crucial role in galvanizing the capacity of institutions and their management capabilities for maximum effect. For instance in Nigeria, the Industrial Training Fund (ITF) established under decree 47, 1971 was mandated to stimulate human performance, improve productivity, undertake supervised industrial work experience (SIWE), vocational and apprentice in Nigerian universities.

The scheme is designed to create a link between universities and industry, bridge the gaps between theory and practice by exposing students to out-of-classroom industrial and world of work experiences and build their capacity for entrepreneurship or self-employment. As school-to- work programme that ensures smooth transition of students to industry and business institutions, its activities has been less impactful due to inadequate student placement, lack of supervision and rejection of student-trainees in some cases by public institutions, local and multi-national organizations. This explains why government policies have not been able to generate the necessary capacity for enhancing the relevance of university education in Nigeria. As a result, such linkages have become ineffective in achieving its objective of transferrable skill development, improving work experience, providing practical and industrial orientation that leads to better career choice in entrepreneurship. Ikpesu (2014) however advocated for the need to strengthen the Supervised Work Experience (SIWE) and National Directory for Employment (NDE) to promote cooperation with industry and business institutions to facilitate the school-to-work transition and offers practical entrepreneurial orientation for immediacy of employment in career related areas. Industries are major partners in both developed and third world economies, as consumers of the outputs from the universities must be involved in operationalizing and managing the curriculum.

Interventions of industry essentially should improve the overall quality of educational outputs and raise generation of young entrepreneurs to compete in global economy. In this context, Okebukola in Ikpesu (2014) refers to entrepreneurial education as an offering which tools learners with knowledge, skills and attitudes to be an entrepreneur-an innovator, the person who develops a new product, a new market, or a new means of production responsible for fostering entrepreneurial mindsets, attitudes and skills covering a range of aspects such as idea generation, start-up, growth and innovation for economic growth. According to Bush and Bell (2005) highly educated workforce promotes flexibility in an era of technological change and developed countries seek to retain their strong economies by investing heavily in education to prepare workers with basic and advanced skills. Entrepreneurship education energizes students to be self-reliance, independent, develop passion for business in order to become income-producing citizens. Entrepreneurial education, is therefore, believe to provide students with relevant employable and income generating skills for operating, managing small project successfully. UNIDO (2007) equally observed that providing generation of young people with access to employment, livelihood opportunities, credit and business coaching remain absolutely essential to securing a more peaceful and prosperous future for all. It is therefore a progressive lifelong learning experience that offers young people with organizational skills, time management, risk management skill, leadership development and 
social networking. In addition, it develops the learner's entrepreneurial personality, character, attitudes and skills necessary for creating business enterprises, employment and wealth generation. These entrepreneurial characteristics are prerequisites for developing boldness, willingness and ability to sift out or identify investment opportunity in their local environment, set up and operate small and medium enterprises successfully. UNESCO (2008: 10) interregional seminar hosted in Bangkok, Thailand defined entrepreneurship education to include all kinds of experiences that give students ability and vision of how to access and transform opportunity of different kind which transcends beyond business creation to increasing students' ability to anticipate and respond to societal changes. In another perspective, it is an education and training which allows students to develop and use their creativity, take initiatives, responsibility and risks. According to Tulgan, (1999) the principal reason for entrepreneurship education is to develop entrepreneurial capacities and mindsets. Sulaiman (2010) career orientation influences individual future actions and those with different kinds of career motivations can be expected to seek different types of entrepreneurial events and learning situations.

Entrepreneurial orientation is a process of training which offer students access to entrepreneurial information that improves their foresight, raise awareness and provide them relevant exposure capable of developing strong mental picture of entrepreneurship. David McClelland (1964) in Ottih (2011) conducted the Kakinada experiment with the objective of breaking the barrier of limited aspiration in individuals by inducing achievement motivation. A sample of 52 persons split into three groups undergone three months orientation programme at Small Industry Extension Training (SIET) Institute at Hyderabad. Participants' imagination and behaviour significantly improved and enhanced their performance. Thus, the presidential committee was mandated to set action plan for the take-off of entrepreneurship education in all higher education institutions and seek collaboration with development partners in bringing world best practices to the programme (Uwani in Okebukola 2011). Industrial exposure is capable of changing students long standing take-the-job mindsets to favour emergence of small and medium business enterprises. But unfortunately, private sector and development partners' active participation in curriculum organization, implementation, financing and management of entrepreneurship education have remained abysmally low and limiting students' exposure to relevant industrial and entrepreneurial experiences. How does universities- industry linkages contribute to entrepreneurship education development?, What are the various implications of university-industry linkages to students' entrepreneurial orientation?. These questions set the pace for investigation and contributing to the conceptual literature of entrepreneurship.

\section{University - Industry Linkages and Students Entrepreneurial Orientation Development} Literature abounds with striking scientific testimony of government- University - industry linkages, cooperation in developing competitive and responsible entrepreneurial capacity of students in developed economies. Universities in economic disadvantaged countries undergoing sharp falls in state funding are now under pressure to look beyond subventions or seed money from government. Non-traditional means of fund and student fees are being used by universities to shore up their revenue. Incessant fee increment experienced in public universities now threatens their statutory responsibility and constantly triggers off crises in most universities in Nigeria and other Africa countries. It is obvious therefore that fees increment is no longer the best of alternative as today universities can only survive by their commitment to research and development, commitment to entrepreneurship and linkages with local and international organizations. The gaps between university -industry and business institutions in Nigeria have become a topical issue of public concern amongst 
stakeholders. Linkages with industry are now being canvassed for by governments and institutional managers to re-invent the tradition of universities, inculcate in students practical and entrepreneurial skills for personal survival and to achieve key objectives of universities. Although this tripartite relationship can also be seen across universities in Nigeria but it varies in its structure, governance, operation and management. Nelson (2007) had observed that government policy frameworks and reforms should be able to galvanize the capacity of institutions to attract industry to invest in R\&D. In fact, government policy at one end open an avenue for linkages between academia and applied research by bringing together a body of industry and academia that have bred collaboration, knowledge exchange to promote entrepreneurship. This new culture helps universities to embrace the concept of economic development.

Universities are now being seen as a sector rather than institution contributing to economic growth through their human capital development function, research and technology transfer. Importantly, universities have obligation to educate, train and produce graduates to understand enterprise culture and have increasing awareness of the need of the industry and commerce, flexible to learn and adapt to change in the world of work. Nimi-Briggs (2012) noted that one important way of assessing the value of university education, is to evaluate the quality of the educational process experienced by students. Mayer in Anyamele, Nwabueze \& Ememe (2009) believed that the task of university across the globe is to develop students that possess seven key competency strands of collecting, analyzing and organizing information, communicating ideas and information, planning and organizing activities, working with others in team, using mathematic ideas and techniques, solving problems and using technology in work environment and other societal settings. Universities in recent times have been striving to inculcate in students entrepreneurial skills essential for responding positively to the needs of the economy; gain greater commercial and industrial relevance. Nimi-Briggs (2012) equally asserts that university attracts to its fold deserving students with aptitude and appetite to learn and systematically taking them through courses of studies to acquire knowledge and skills in order to become responsible and useful members of the community. Entrepreneurship education therefore changes the orientation and attitude of young people by equipping them with business skills and knowledge to start and manage a business enterprise ( Iloh, 1991 in Ughamadu, 2009). Entrepreneurship education, in other words, exposes students to real life learning experiences required for critical thinking, risk taking, manage circumstances and learn from the outcome. It propels their ability to turn ideas into action, it includes creativity, innovation, showing initiative and risk taking, as well as the ability to plan and manage projects in order to achieve objectives (European Commission, 2011). Entrepreneurship is a deliberate action undertaken by person or persons for exploring and exploiting investment opportunities. This action is essentially guided by ability to identify business activities, decision-making concerning opportunity to exploit and pooling required resources together for production and possible future diversification. Thus, entrepreneurship is an approach to life that involves thinking, reasoning and acting that is opportunity -obsessed, holistic and leadership balanced (Mariotti, 2006). Many studies including Alarape (1990), Streeter et al, (2002, and Blenker et al, 2004) in Lasisi and Nwoke (2009) proposed three distinct models of entrepreneurship education to include composite, integrated and network for effective implementation of entrepreneurship education programme. Network model is a partnership adopted by institution for implementing entrepreneurship education due to universities' limited financial resources, institutional inability to meet competing needs and growth in entrepreneurial content and pedagogies. The model emphasizes collaboration, share responsibility and commitment amongst cooperative universities. Participating universities, therefore, promote inter-institutional contribution of resources in order to maximize the 
benefits of cooperation. Besides, the challenges and opportunities face by universities in the transition into an entrepreneurial institution revolve around its research strength and nature of the related industries and the region in particular. On the other hand, universities in 21st century drive of becoming entrepreneurial must expectedly have capacity to link themselves to the wider market of ideas in society and business institutions. Entrepreneurship accounts for creation of new business opportunities and contributes approximately one-half of the differences in GDP growth between countries. Henderson in Sulaiman (2010) equally supported this empirical conclusion that entrepreneurs significantly impact economic activity at a more local level through fostering localized job creation, increasing wealth and local incomes thereby integrating local economies to the larger, global economy. Kaegon (2009) citing examples of Germany; Norway noted the evolvement of entrepreneurship training into unique educational oriented programmes for inculcating innovative spirit in young people. This however requires setting up an enabling environment by universities to drive creativity, stir up students to thrive, seek out and nurse ideas from the cradle of invention to full commercialization. Entrepreneurs immensely affect national economy, according to United State Census Bureau Survey of Business Owners (2009) cited by Oko-Jaja (2009) contribute three quarter (3/4) of United State businesses and generate more than half of the nation's gross domestic products and the principal source of new jobs.

Achieving these underlined objectives by universities demands strategic partnership and cooperation with industry, business entrepreneurs for technical support, staff and student exchange programme in special areas of interest. This trajectory conceptual perspective of university-industry linkages in Nigeria can be better explained by the triple helix model. Current growing body of literature underscores the importance of university-industrygovernment relations provide students pathway for gaining practical industrial exposure and entrepreneurial orientation. In advancing the culture of the triple-helix, Shattock (2001) posits that although universities are funded for teaching and research by the state, they look to industry because it offers not only interesting research problems that individual academics are keen to tackle, but have experimental facilities or testing facilities that are not available in university laboratories. He further maintains that industry while conducting its own R\&D, on the other hand; equally recognize the value of outsourcing a good deal of its upstream research to university laboratories and bringing complex problems to universities to be solved by leading academics. Buchbinder and Newson (1985) also add to the above observation that for universities, these linkages anticipate a new source of funds at a time of financial crunch; for corporations, the acquisition of an infrastructure to meet research and manpower training needs at a time nation's economy is faced with intensive competition from foreign producers. From institutional perspective, many universities are gradually developing this new culture. Linkages, partnership with industry is contributing significantly to the key function of teaching, learning and research in Nigerian Universities. These core roles of the university community are now being influenced by interface with industry. For instance, University of Portharcourt (UP) is a Federal Government institution established in Rivers State, South-South Nigeria. The region is endowed with abundant Natural resources, multi-national firms and is the commercial nerve of Nigeria's economy. The institution's International Linkages Center is set up with the objectives to promote exchange of staff and students, share research projects, provide joint degree site for shared curricular with international universities. The center attracted collaborations with numbers of multi-national companies in and outside Nigeria. These collaborations have been gainfully used by the University of Portharcourt to establish NLG Gas institute, NNPC / AGIP information technology center providing professional development and training programmes for institutions, students and industries. The Center for 
health and Development built by joint collaboration with university of Toronto and Associations of universities and colleges of Canada (AUCC) is involved in academic work and projects that have beneficiary value to the university community. Furthermore, Schlumberger Nigeria limited and MacArthur Foundation partnered with University of Portharcourt to build the Senate house which effectively coordinates all activities of its administration. Institute of Petroleum Studies (IPS) was established by the university in 2003 through the support of Nigeria National Petroleum Company (NNPC) and Total Oil Company collaborates with IFP, global petroleum engineering tertiary education institution in Paris offering professional training, curriculum development; excursion and joint degree award in Nigeria and IFP School in Paris, France. These activities have significant impact on the core traditions of university and provide better environment for scholarship. Gundmund and Michaela (2000) outlined the essential roles of university-industry relations to include teaching and research, student placement schemes, staff exchanges, consultancy services, continuing professional development and creation of spin-off enterprises for the joint commercialization of R\&D products. Etzkowitz, 1998 in Shattock, (2000) the literature regularly refers to the triple-helix of university-industry-government relations or concepts of entrepreneurial science ( Etzkowitz and Webster, 1998). This however underpins the significance and impact of university in economic development, wealth creation, commercialization of science and long term consequences of globalization and its localization.

Recent development in University - Government - Industry linkages has significantly improved university fortunes in Nigeria. In Nigeria, universities are supported by government and industry through the Tertiary Education Trust Fund (TETFund). The fund was established by TETFund act, 2011 as an intervention agency with the mandate to fund essential physical infrastructure for teaching and learning, provision of instructional material and equipment, research and publication, academic staff training and development, promoting creative and innovative approaches to educational learning and services. The agency however derives its funds from taxable profits of registered organizations with strong operational and verifiable assets by imposing, managing and disbursing the tax to public tertiary institutions in Nigeria. A collection of minimum two percent of their earnings is payable to the agency to support higher education and fund special entrepreneurship project to encourage students vocational skills development and entrepreneurship training. This evolving approach in Nigeria higher education increases government-industry investment in innovative research, development and education determines the global competitiveness of nations (Suleiman, 2014). This policy however justifies the need to allocate sufficient resources to scientific research that has capacity to translate Nigeria into knowledge economy. Thus, massive qualitative human capital development with increasing emphasis on technology and product development are factored into the economic growth chain.

\section{HYPOTHESIS}

1. There is no significant relationship between the contribution of university - industry linkages and students' entrepreneurial orientation in public universities.

\section{Methodology}

The population is made up of all academic administrators charge with various aspects of academic administration and management of universities in Rivers State. At the time of the research, the State hosts three strategic public universities with strong industrial presence the largest in South-South geo-political zone. The population, therefore, consists of 160 academic administrators in three public universities. Academic administrators were purposively sampled in public universities because of their role in designing policy frameworks and 
curriculum reforms that strengthens linkages with industry in their respective universities. For the purpose of this study, two independent measurement scales having four Likert points containing 13-item each measure the critical contributions of university-industry linkages and its implications to students' entrepreneurial orientation (EO). In addition, one null hypothesis was tested at 0.05 level of significance to determine relationship between the independent and dependent variables. However data successfully retrieved from 150 respondents were analyzed with mean and standard deviation statistics while hypothesis tested with Pearson product moment correlation coefficient converted to Z-test establish the significance of the variables measured.

\section{Result Presentation}

Table 1: Mean Analyses of the contribution of university - Industry Linkages for developing entrepreneurship Education in Public Universities

\begin{tabular}{lll}
\hline $\mathbf{s} / \mathbf{n} \quad \mathbf{N}=\mathbf{1 5 0}$ & $\bar{X}$ & Stdev \\
\hline 1. using industrial entrepreneurs for part time teaching & 2.72 & 1.0157 \\
2. Setting up centre for joint research & 2.68 & 1.1308 \\
3. Attract funds from industry & 2.57 & 1.0634 \\
4. Involving students in project management & 2.84 & 0.9579 \\
5. Offer sabbaticals to senior academia & 2.67 & 1.1068 \\
6. Share technical expertise and experience & 2,54 & 1.0266 \\
7. Exposure to new research techniques & 2.76 & 1.0275 \\
8. Support university with laboratory equipment & 2.56 & 0.9920 \\
9. Offer professional development services & 2.97 & 1.0127 \\
10. Participate in curriculum organization & 2.83 & 1.0323 \\
11. Split-site degree programme to encourage & & \\
knowledge exchange & 2.90 & 1.0122 \\
12. Financing entrepreneurship projects & 2.59 & 1.0233 \\
13. Supporting university with new technology & 2.51 & 1.0466
\end{tabular}

The means in the above table representing various aspects of university - industry linkages ranked high by respondents validated its significant contributions towards developing entrepreneurship education in public universities 
Table 2: Mean Analysis of implications of University - Industry Linkages and Students'

Entrepreneurial Orientation.

\begin{tabular}{llll}
\hline $\mathbf{s} / \mathbf{n}$ & $\mathbf{N}=\mathbf{1 5 0}$ & $\bar{X}$ & $\mathbf{s t d e v}$ \\
\hline 1. Developing student entrepreneurial personality & 2.53 & 0.9592 \\
2. Developing positive attitude for independence & 2.65 & 1.0486 \\
3. foresight for identifying investment opportunities & 2.54 & 1.0522 \\
4. strong desire for setting up and managing small project & & \\
$\quad$ successfully & 3.12 & 0.9892 \\
5. Access to entrepreneurial information & 2.77 & 1.0305 \\
6. Raising awareness level about business & 2.81 & 1.0661 \\
7. Develop ability to organize information & 2.56 & 0.8927 \\
8. Avenue for changing student take-the-job mentality & 3.00 & 0.9011 \\
9. Conceive and translate ideas into reality & 2.58 & 0.8906 \\
10. Develop ability to solve problem effectively & 2.51 & 1.0467 \\
11. Avenue for developing organizational skills & 2.54 & 0.9795 \\
12. Acquire risk management skills & 2.74 & 0.9581 \\
13. Acquire time management skills & 2.72 & 0.9904
\end{tabular}

The above means that outlined the consequences of university - industry linkages were highly rated by respondents as a means for developing students' entrepreneurial orientation in public universities.

Table 3: Correlational analysis of the University - Industry Linkages as determinant of Students Entrepreneurial Orientation

\begin{tabular}{lllllll}
\hline model & $\mathrm{n}$ & $\mathrm{r}$ & $\mathrm{df}$ & $\mathrm{z}$-rcal & z-rcrit & remark \\
& & & & & \\
\hline
\end{tabular}

U-IL

\begin{tabular}{lllllll} 
& 150 & +0.376 & 149 & 0.561 & 0.195 & sig \\
EO & & & & & & \\
\hline Key: & &
\end{tabular}

Key:

U-IL - University - Industry Linkages

EO - Entrepreneurship Orientation

The coefficient result +0.376 with correlation value of Z-rcal 0.561 greater than Z-rcrit 0.195 validating the intercorrelation of variables explained how industrial experiences significantly enriched students' entrepreneurial orientation in universities.

\section{Discussion of Findings}

Global recognition of entrepreneurs as catalysts for national economic development constantly put pressure on universities to prepare students who can respond positively to societal changes. In achieving the desired objective by universities industry involvement is crucial in building the capacity of students to contribute to national economy. The various aspects of university - industry linkages examined affirm the significant contributions of industry to universities. Institutional linkages are strategic facilitator of outward movement and exposure 
of students to real life experiences, for developing their technical and vocational skills. Some universities within the South-South in Nigeria are gradually evolving strategic partnership and cooperation with industry, business entrepreneurs taking advantage of the regional economy to seek for technical support, staff and student exchange programme and to attract funding. Funding of universities across the globe has assumed new dimension involving tripartite contribution among institution - Government- industry. From the global experience, research conducted for the Kauffman Foundation reported that 400 chairs of entrepreneurship in the United States amount to approximately USD 1 billion. Entrepreneurship centres and chaired professorships of entrepreneurship are funded by successful entrepreneurs who graduated from their institutions (Katz 2004, Wilson 2008). Linkages are assuming unusual popularity as a platform for technology transfer, knowledge sharing and seeking support by universities from industry. Many universities evolving and including this global trend into their traditional role to attract and contract entrepreneurs for teaching, research, share project management, bring in new research techniques, sharing technical expertise, participate in curriculum organization and sabbaticals for senior academics for continuous professional development. Oftentimes, linkages in universities are influenced by outward -looking academic staff having wide range of experience in academia and industry. Furthermore, the findings have also shown that collaboration of universities - industry provide the platform for universities in developing countries to re-model, replace old and low-level technology, equip their laboratory with new technology, finance entrepreneurship project, and develop in students ability to solve problem and continuous professional development. For instance, the International Linkages Center, University of Portharcourt (UP) is very strong and vibrant center that maintains linkages with numbers of international institutions for staff and student exchange programme, spilt- site degree programme and joint research that greatly impact various aspects of the institution.

Industrial training undertaken by students is mandatory pre-graduation requirement in Nigerian universities coordinated by the Industrial Training Fund (ITF) established under decree 47, 1971 for supervised industrial work experience (SIWE), stimulate human performance, and improve productivity. But in Nigeria, students take personal responsibility to scouts for placements in the industry. Its overall impact has been limited by lack of placement, lack of supervision and rejection of students by both public and private institutions. However this is different from what the practice is in University of Sao Paulo (USP) in Brazil, a consortium of enterprises and university representatives jointly revise undergraduate curriculum, students carry out internship in SMEs sector and topics of Ph.D theses especially in technology fields are increasingly determined by research grants provided from private enterprises. A link with industry although bridge the gaps between theory and practice give access to entrepreneurial information, raise awareness about business, change their mental orientation, develop capacity for organizational, risk taking and time management skills which are vital entrepreneurial character for self-employment. International Institute for Educational Planning (IIEP, 2001) had noted that research and teaching capacity, industrial base, traditional interaction practiced between higher education and enterprises and entrepreneurial culture within higher education sector are boundary conditions that define the nature of interactions. In conclusion, support from industry is not only useful but determine the content of academic curriculum, improve both undergraduate and graduate teaching, influence students' community with necessary orientation that changes their attitude towards life and channels their mindsets to favour emergence of business enterprises. It impacts the general psych of students by developing positive personality, attitudes, independence; enhance foresights of students to sift out opportunity, turn ideas into economic goods and services for 
societal development. These entrepreneurial attributes are major character of entrepreneurs. Emergence of entrepreneurs in third world countries especially Nigeria will strengthen the economy against recession by creating multiple new business opportunities. Current scientific reports validated the relationship between entrepreneurship and economic development. The differences in GDP growth between countries has been attributed to the contributions of entrepreneurial activities. Henderson in Sulaiman (2010) equally supported this empirical conclusion that entrepreneurs significantly impact economic activity at a more local level through fostering localized job creation, increasing wealth and local incomes thereby integrating local economies to the larger, global economy. Therefore, the various policy frameworks must be overhauled and strengthened by Governments to drive the objectives of entrepreneurship education of producing students with high entrepreneurial contents that can fit well into self-employment and global labour market of tomorrow.

\section{References}

Anyamele, S.C., Nwabueze, A.L. \& Ememe, O.N. (2009). The role of higher education in managing entrepreneurship for economic development in Nigeria. African Journal of Educational Research and Development 3(2)

Buchbinder, H., Newson, J. (1985). Corporate - University linkages and the Scientific - Technical Revolution. Interchange,vol. 16, No. 3

Bush, T. \& Bell, L. (2005). The Principles and Practice of Educational Management. London: Paul chapman Publishing. www.paulchapmanpublishinng.co.uk

European Commission (2011). Entrepreneurship Education: Enabling Teachers as a critical success factor. Final report, Brussels

Gundmund, H., Michaela, M. (2000). Trends in the management of university-industry linkages: What challenges are ahead?. International Institute for Educational Planning. http://www.unesco.org/iiep

Ikpesu, O.C . (2014). Entrepreneurial Human Capital Development and Economic Future of Nigerian Graduates. Developing Country Studies Vol. 4 No 12.

International Institute for Educational Planning (2000). Management of University- Industry Linkages, Policy Forum. No 11, Paris

Lasisi, R \& Nwoke, B.N (2009). Entrepreneurship Education and Human Capital Development: Lesson from A Nigerian University. African Journal of Educational Research and Development 3(2)

Mariotti, S. (2006). Entrepreneurship: How to start and operate a small business. African Journal of Entrepreneurship, 1(2)

Nelson, J. (2007) ). Building Linkages for Competitive and Responsible Entrepreneurship. www.unido.org

Nimi-Briggs, D. (2012). Fulfilling the Mandate: Rivers State University of Science and Technology 24th Convocation Lecture. Portharcourt 3rd May.

Okebukola, P. A. (2011). Entrepreneurship in University Education: Beyond Talk. 27th Convocation Lecture, University of Portharcourt, Nigeria June 16.

Shattock, M.L (2001). In what way do changing university -industry relations affect the management of higher education institutions. http://www.unesco.org/iiep

Sulaiman, S. N (2010). Entrepreneurship. Theories, Concepts \& Persepectives. Triumph Publishing Company Limited, Kano

Suleiman, (2014). Institutionalization of research and development (R\&D) as the launch pad for Nigeria technological revolution. 62th University of Ibadan interdisciplinary research discourse.

Tulgan, B. (1999). Generation X: The future is now. Entrepreneur of the Year Magazine. Fall, 42

Ughamadu,U. (2009). Integration of entrepreneurship education into the Nigerian university curriculum. African Journal of Educational Research And Development (AJERD)vol3:2. University of Portharcourt, Nigeria.

UNESCO (2008). Inter Regional Seminar on Promoting Entrepreneurship Education in Schools, Bangkok, Thailand. 